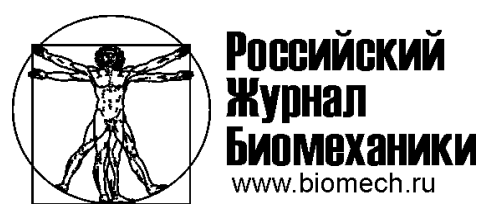

\title{
БИОМЕХАНИЧЕСКОЕ МОДЕЛИРОВАНИЕ НАПРЯЖЕННО- ДЕФОРМИРОВАННОГО СОСТОЯНИЯ РЕСТАВРИРОВАННОГО ЗУБА ПОД ОККЛЮЗИОННОЙ НАГРУЗКОЙ ПРИ РАЗЛИЧНЫХ СПОСОБАХ ФИКСАЦИИ ШТИФТА В КОРНЕВОМ КАНАЛЕ
}

\author{
Н.О. Бессуднова ${ }^{1}$, Е.Е. Ципоруха ${ }^{1}$, С.Б. Вениг ${ }^{2}$ \\ ${ }^{1}$ Кафедра медицинской фризики Саратовского национального исследовательского государственного \\ университета им. Н.Г. Чернышевского, Россия, 410012, Саратов, ул. Астраханская, 83, e-mail: \\ katrine993@mail.ru \\ 2 Кафедра материаловедения, технологии и управления качеством Саратовского национального \\ исследовательского государственного университета им. Н.Г. Чернышевского, Россия, 410012, Саратов, \\ ул. Астраханская, 83, e-mail: nano-bio@sgu.ru
}

\begin{abstract}
Аннотация. В настоящем исследовании методы компьютерной биомеханики применены для оценки надежности реставрационных конструкций эндодонтически леченых зубов. Представлены результаты численного моделирования биомеханического поведения реставрированного центрального резца верхней челюсти под окклюзионной нагрузкой в $100 \mathrm{H}$ при различных типах прикуса. С этой целью построена трехмерная модель зуба, включающая в себя элементы сохранившихся твердых тканей, периодонтальную связку с участком альвеолярной кости и элементы постэндодонтической реставрации, и проведены вариативные расчеты напряженно-деформированных состояний в структурах зуба под окклюзионной нагрузкой при различных комбинациях материалов и дизайне конструкций. В частности, изучено влияние материалов армирующего элемента и фиксирующего цемента, а также способов фиксации штифта в корневом канале на функциональные характеристики реставрированного зуба. Проведено сравнение напряженно-деформированных состояний зубов, восстановленных с применением фиксирующего стекловолоконный штифт композитного полимерного цемента RelyX $A R C$ (3M ESPE), предполагающего удаление разрушенного (смазанного) слоя дентина перед нанесением слоя адгезивной системы, и самопротравливающего композитного полимерного цемента RelyX Unicem Self-Adhesive Universal Resin Cement (3M ESPE), сохраняющего смазанный слой, для случаев прямого и физиологического прикусов. Спроектированная 3D-модель может быть применена для доклинической оценки и сравнения долговечности различных видов постэндодонтических реставрационных конструкций.
\end{abstract}

Ключевые слова: биомеханическое моделирование, прототипирование, численные методы, метод конечных элементов, реставрационная стоматология, адгезивные материалы и технологии, армирующие конструкции.

\section{ВВЕДЕНИЕ}

В реставрационной стоматологии прогноз в отношении депульпированных зубов во многом определяется способом их последующего восстановления. В настоящее время биомеханические аспекты восстановления эндодонтически леченых

(C) Бессуднова Н.О., Ципоруха Е.Е., Вениг С.Б., 2015

Бессуднова Надежда Олеговна, к.ф.-м.н., доцент кафедры медицинской физики, Саратов

Ципоруха Екатерина Евгеньевна, студентка кафедры медицинской физики, Саратов

Вениг Сергей Борисович, д.ф.-м.н., заведующий кафедрой материаловедения, технологии и управления качеством, Саратов 
зубов являются предметом постоянного внимания клиницистов и инженеров, чьи научные интересы лежат в области реставрационной стоматологии и стоматологического материаловедения $[4,6]$.

В связи с этим практически значимой задачей является оптимизация методов реставрации таких зубов с точки зрения применяемых материалов и структур.

В мировой литературе представлены данные о влиянии множества факторов на функциональные характеристики реставрированных зубов под внешней нагрузкой, в частности, изучено влияние физико-химических свойств реставрационных материалов; материала и геометрии армирующих внутрикальных конструкций; количества сохранившихся твердых тканей зуба; влияние поддерживающего аппарата, включающего периодонтальную связку и костные структуры, и др. На сегодняшний день большинство исследователей сходятся во мнении о преимуществах применения стекловолоконных армирующих элементов цилиндроконической формы с целью восстановления целостности структуры зуба после проведенного эндодонтического лечения.

Стекловолоконный штифт имеет ряд важных особенностей: его можно легко припасовать в корневом канале, после фиксации при необходимости извлечь, стерилизовать; он не изменяет цвет реставрации; биологически инертен. Стекловолокно имеет сравнимый с дентином модуль эластичности, обладает способностью к адгезивному соединению с дентином и композитом, в результате чего не только улучшается ретенция с реставрационным материалом, но и действительно укрепляются твердые ткани зуба. Однако остаются недостаточно изученными вопросы влияния характеристик адгезивного соединения, используемого при фиксации штифта в корневом канале, на функциональные возможности реставрированного зуба под нагрузкой.

В связи с вышесказанным целью настоящего исследования является изучение влияния параметров адгезивного соединения на биомеханические характеристики реставрированного зуба после проведенного эндодонтического лечения.

\section{МАТЕРИАЛЫ И МЕТОДЫ}

Прототипом для создания 3D-модели был выбран нереставрированный центральный резец верхней челюсти. Все необходимые элементы реставрации эндодонтически леченого зуба проектировались с помощью САПР Solid Works 2010 (Solid Works Corp.). При исследовании напряженно-деформированного состояния применялся пакет прикладных программ ANSYS 14 (ANSYS Inc).

Модель собиралась по сечениям, метрические характеристики которых указаны в табл. 1. Все необходимые замеры образца были выполнены предварительно при помощи микрометра Electronic Outside Micrometer (10-25 мм, цена деления 0,001 мм).

В процессе моделирования были учтены следующие характерные особенности комплекса «реставрированный зуб-периодонтальная связка-альвеолярная кость» [7]:

- периодонтальная связка имеет максимальную толщину 40 мкм у апикального отверстия, минимальную - 150 мкм в средней трети корня;

- толщина цемента корня вблизи апикального отверстия составляет 970 мкм, вблизи шейки зуба - 50 мкм;

- гуттаперча обтурирует нижнюю треть корневого канала;

- реставрация проводилась при помощи адгезивной системы Single Bond (3M ESPE); толщина слоя составила 20 мкм;

- толщина нанесения композиционного лютингового цемента - около 50 мкм; 
Метрические характеристики образца

Таблиия 1

\begin{tabular}{|c|c|c|c|c|c|}
\hline Часть зуба & Номер сечения & Большая ось, мм & Малая ось, мм & \multicolumn{2}{|c|}{ Высота образца, мм } \\
\hline \multirow{5}{*}{ Корень } & 1 & 3,531 & 4,406 & \multirow{5}{*}{15,114} & \multirow{8}{*}{25,434} \\
\hline & 2 & 5,205 & 5,454 & & \\
\hline & 3 & 5,672 & 6,611 & & \\
\hline & 4 & 5,890 & 6,799 & & \\
\hline & 5 & 6,369 & 6,809 & & \\
\hline \multirow{3}{*}{ Коронка } & 6 & 6,541 & 7,264 & \multirow{3}{*}{10,629} & \\
\hline & 7 & 8,378 & 6,850 & & \\
\hline & 8 & 8,444 & 2,909 & & \\
\hline
\end{tabular}

- использовался стекловолоконный штифт конической формы RelyX fiber post (3M ESPE) с погружением на 2/3 длины корня (параметры штифта: длина - 16 мм, диаметры - 0,5 и 0,9 мм, конусность - 0,6).

Этапы построения $3 D$-модели:

1. Определение точки начала отсчета и создание вспомогательных плоскостей ориентировочных уровней модели.

2. Построение каркаса внешней оболочки модели (коронковой и корневой частей зуба) путем нанесения эскизов сечений на вспомогательные плоскости (рис. 1).

3. Моделирование сохранившихся твердых тканей зуба (дентина и цемента корня), периодонтальной связки, участка альвеолярной кости и элементов реставрации (обтурированного гуттаперчей корневого канала, штифта конической формы, лютингового композиционного цемента, адгезивных соединений, коронковой части из реставрационного материала).
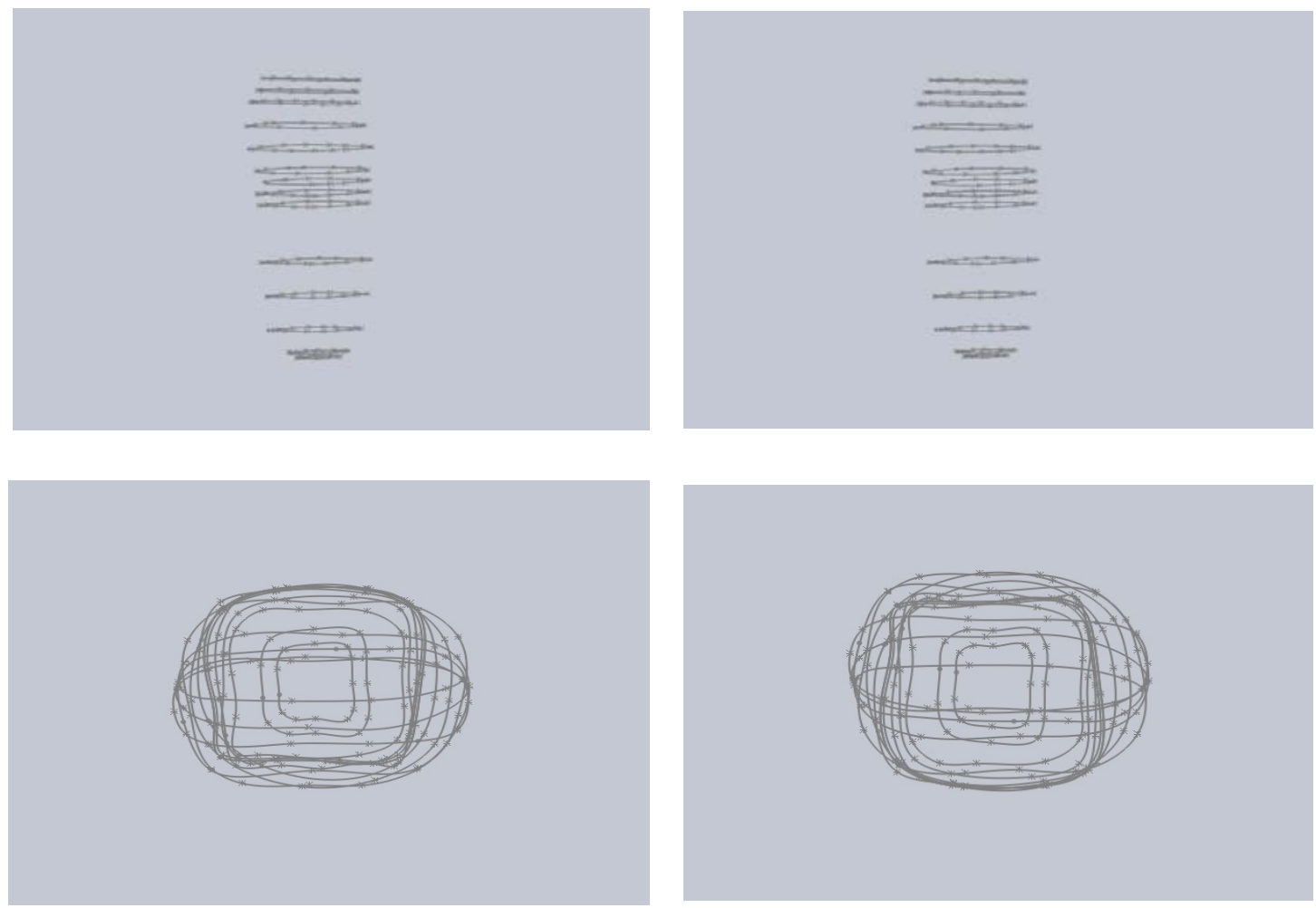

Рис. 1. Каркас внешней оболочки модели 

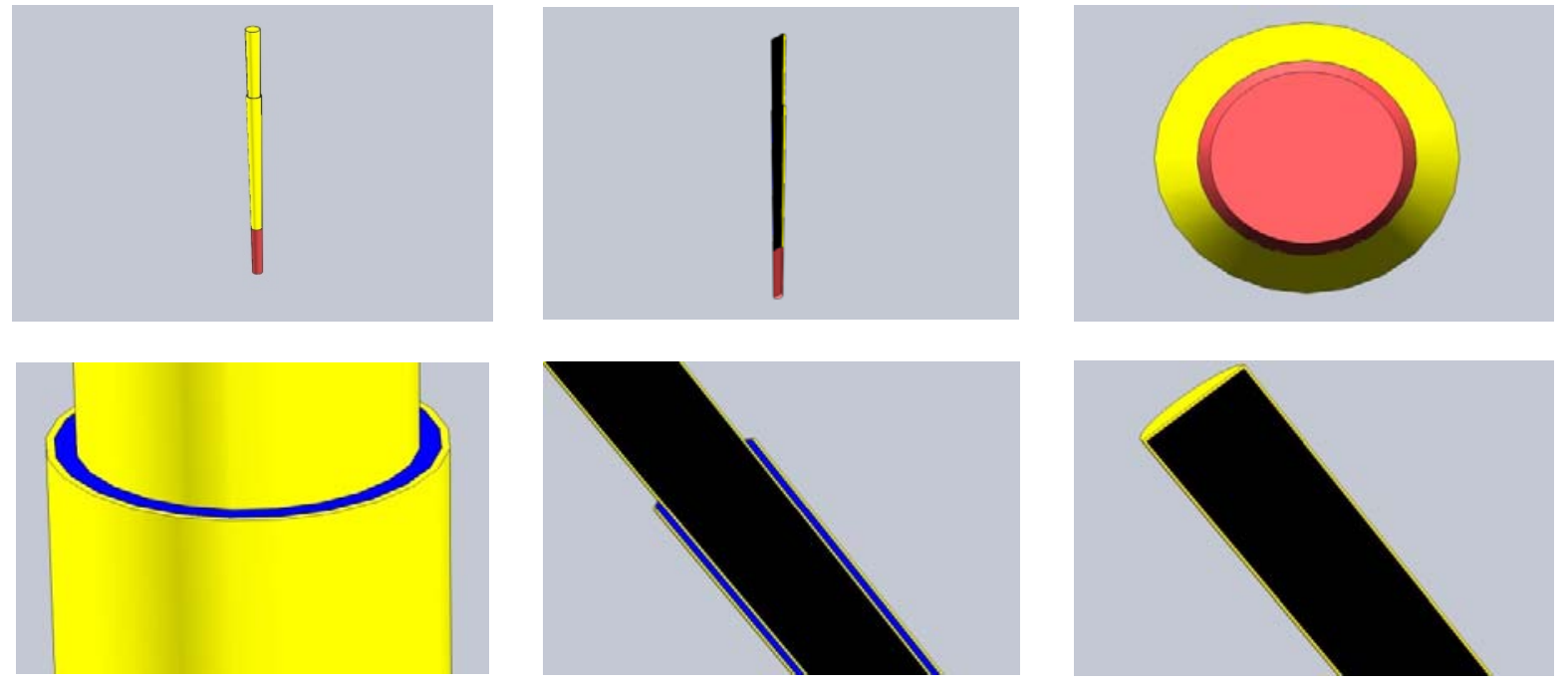

Рис. 2. Внутренняя часть модели зуба, включающая гуттаперчу, штифт, композитный лютинговый цемент и адгезив
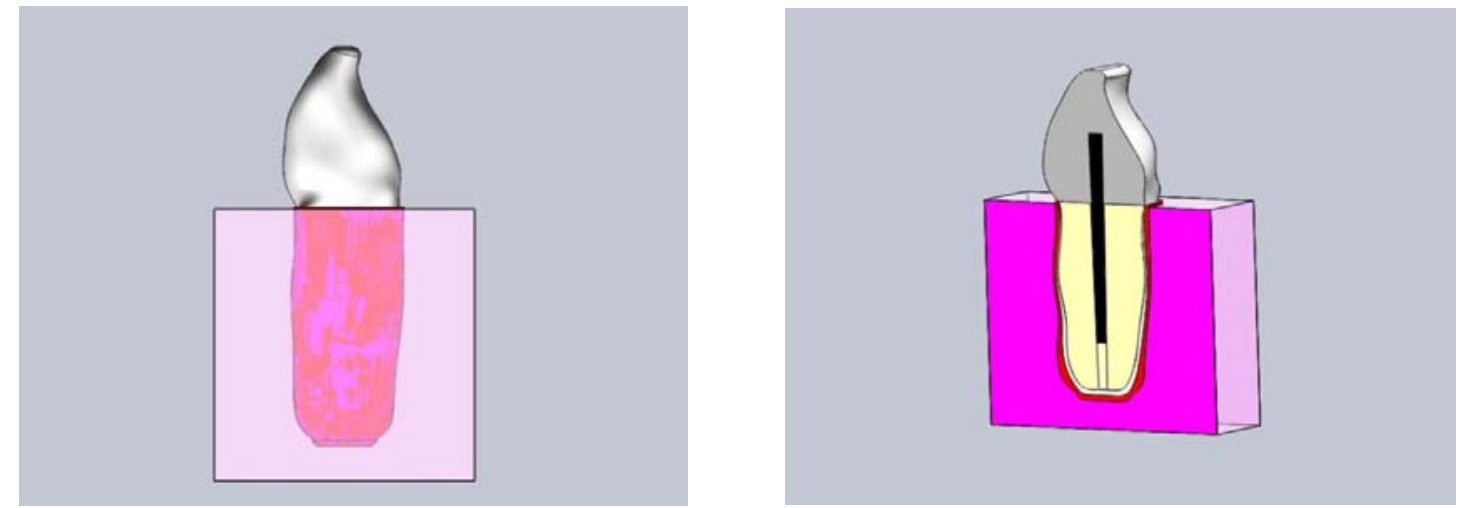

Рис. 3. Готовая модель центрального резца верхней челюсти, построенная в среде Solid Works

Сборка, включающая штифт, лютинговый композиционный цемент, два адгезивных соединения и гуттаперчу, представлена на рис. 2: черным цветом обозначен штифт, желтым - адгезивная система, синим - композиционный лютинговый цемент, розовым - гуттаперча.

На рис. 3 изображена готовая модель реставрированного центрального резца верхней челюсти с учетом поддерживающих его костных структур в различных проекциях.

Разработанная модель включает в себя следующие элементы: дентин, цемент, периодонтальную связку, поддерживающие зуб костные структуры, стекловолоконный штифт, лютинговый цемент, адгезивную систему для фиксации штифта, реставрационный композиционный материал [7].

Влияние свойств адгезивного соединения, используемого при фиксации штифта в корневом канале, на механические характеристики зуба было изучено в среде пакета прикладных программ ANSYS 14.

При исследовании напряженно-деформированного состояния граничные и начальные условия задавались из следующих соображений: альвеолярная кость, периодонтальная связка и корень зуба рассматривались как единая упругая буферная система, причем периодонтальная связка считалась эластичной по сравнению с альвеолярной костью, практически недеформируемой под передаваемой внешней нагрузкой; остальные элементы реставрированного зуба гомологичны, непрерывны и изотропны $[2,7]$. 
в табл. 2.

Физико-механические характеристики используемых материалов представлены

Как было указано выше, исследование напряженно-деформированного состояния было выполнено в программном пакете конечно-элементного анализа ANSYS. Для проведения расчетов импортируемая модель была разбита на множество мелких объемов - тетраэдров [5], минимальная длина ребра которых составляла $7,4573 \cdot 10^{-5}$ м при релевантности сетки 50, числе узлов 132153 и элементов 53392. Оптимальные параметры разбиения выбирались программой автоматически.

Густота сетки армирующей конструкции и коронковой части зуба задавалась выше с применением опции «Body Sizing», поскольку там локализованы интересующие нагрузки: число узлов составляло 134765 , число элементов - 55 022, размер грани элемента в коронковой части - 0,0005 м. Результат разбиения представлен на рис. 4.

С целью имитации физиологического прикуса к модели прикладывалась косонаправленная нагрузка в $100 \mathrm{H}$ под углом $30^{\circ}$ к вертикальной оси зуба [1-3, 5, $7,8]$ и вертикальная нагрузка той же амплитуды - в случае прямого прикуса [8] (рис. 5).

Таблий 2

Упругие свойства используемых материалов

\begin{tabular}{|c|c|c|c|}
\hline № п/ா & Название материала & Модуль Юнга, МПа & Коэффициент Пуассона \\
\hline 1 & Дентин & $18600[2,5,7,8,10]$ & 0,31 \\
\hline 2 & Периодонт & $50[1,5,8,10]$ & 0,45 \\
\hline 3 & Альвеолярная кость & $13800[2,5,8,10]$ & 0,31 \\
\hline 4 & Цемент корня & $22400[2,10]$ & 0,35 \\
\hline 5 & Гуттаперча & $0,69[2,5,7]$ & 0,45 \\
\hline 6 & $\begin{array}{c}\text { Композит для коронковой части } \\
(\text { Eshet } X)\end{array}$ & $7410[1,8]$ & 0,45 \\
\hline 7 & $\begin{array}{c}\text { Стекловолокно для штифта } \\
\text { (RelyX fiber post) }\end{array}$ & $35000[1]$ & 0,3 \\
\hline 8 & $\begin{array}{c}\text { Адгезив стоматологический } \\
\text { (Single Bond) }\end{array}$ & 1380 & 0,3 \\
\hline 9 & $\begin{array}{c}\text { Лютинговый цемент для } \\
\text { применения с адгезивом } \\
\text { отдельным этапом (RelyX } A R C)\end{array}$ & 4920 & 0,27 \\
\hline 10 & $\begin{array}{c}\text { Лютинговый цемент для } \\
\text { применения без адгезива } \\
\text { отдельным этапом (RelyX } \\
\text { Unicem Self-Adhesive Universal } \\
\text { Resin Cement / RelyX u200) }\end{array}$ & 6600 & 0,3 \\
\hline 11 & Сплав титана для штифта & $102000[2,5,10]$ & 0,3 \\
\hline 12 & Стеклоиономерный цемент & $20900[2,5]$ & 0,35 \\
\hline 13 & $\begin{array}{c}\text { Композит для культевой } \\
\text { вкладки }\end{array}$ & $16600[7]$ & 0,24 \\
\hline
\end{tabular}



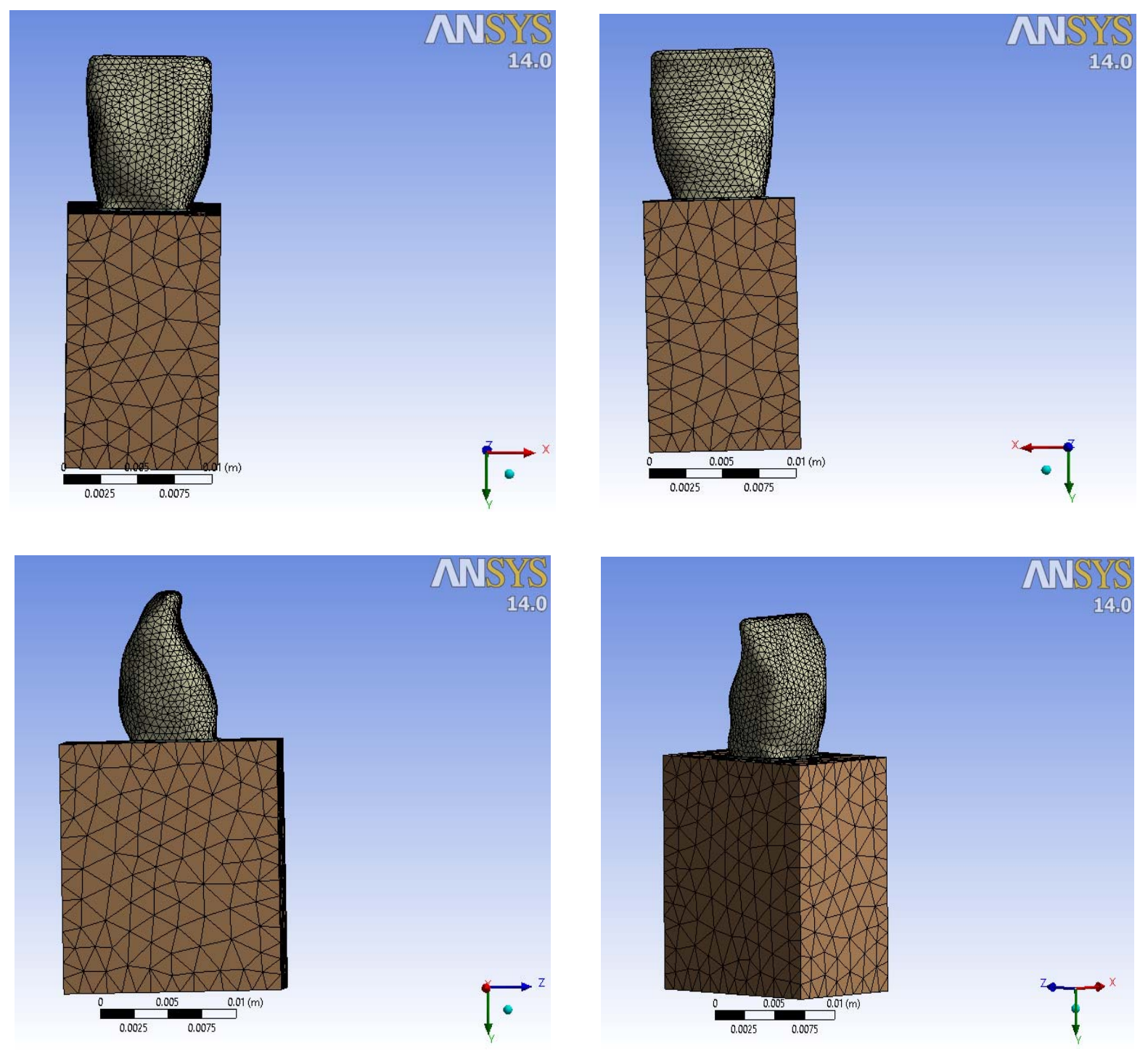

Участок альвеолярной кости с зубом в различных проекциях
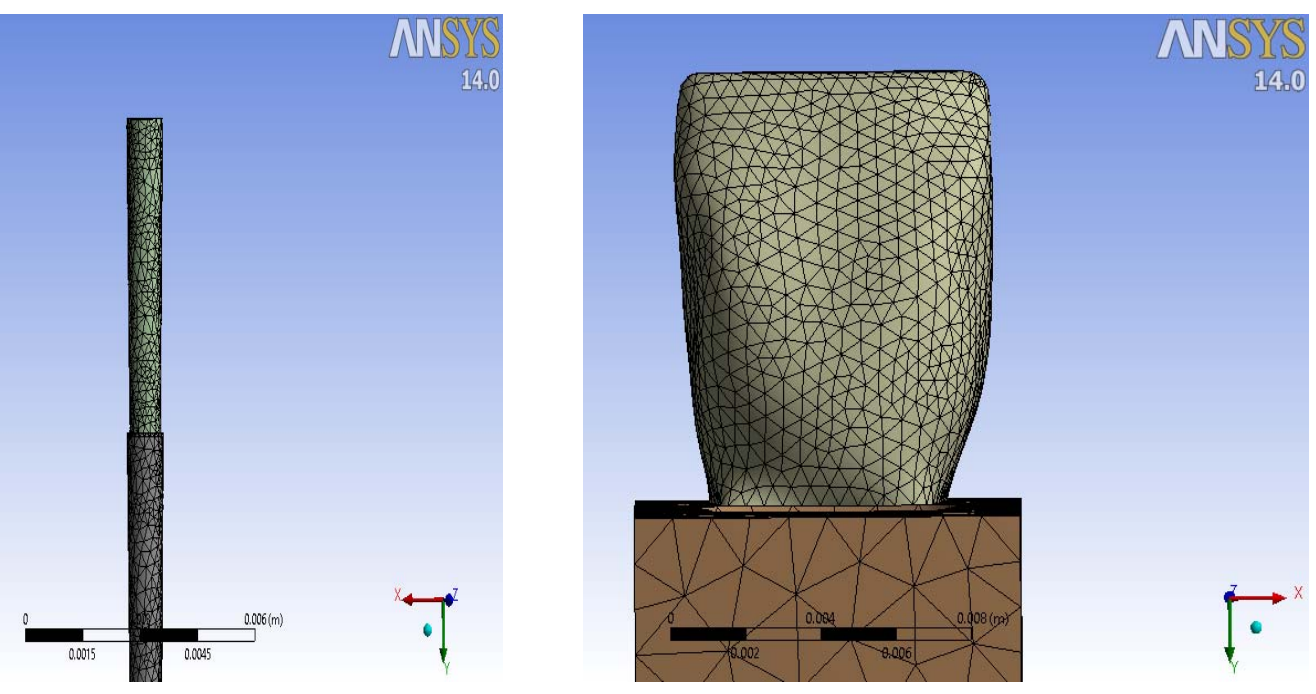

Конечно-элементная модель штифта (слева) и коронки (справа)

Рис. 4. Разбиение модели на конечные элементы 
Физиологический прикус

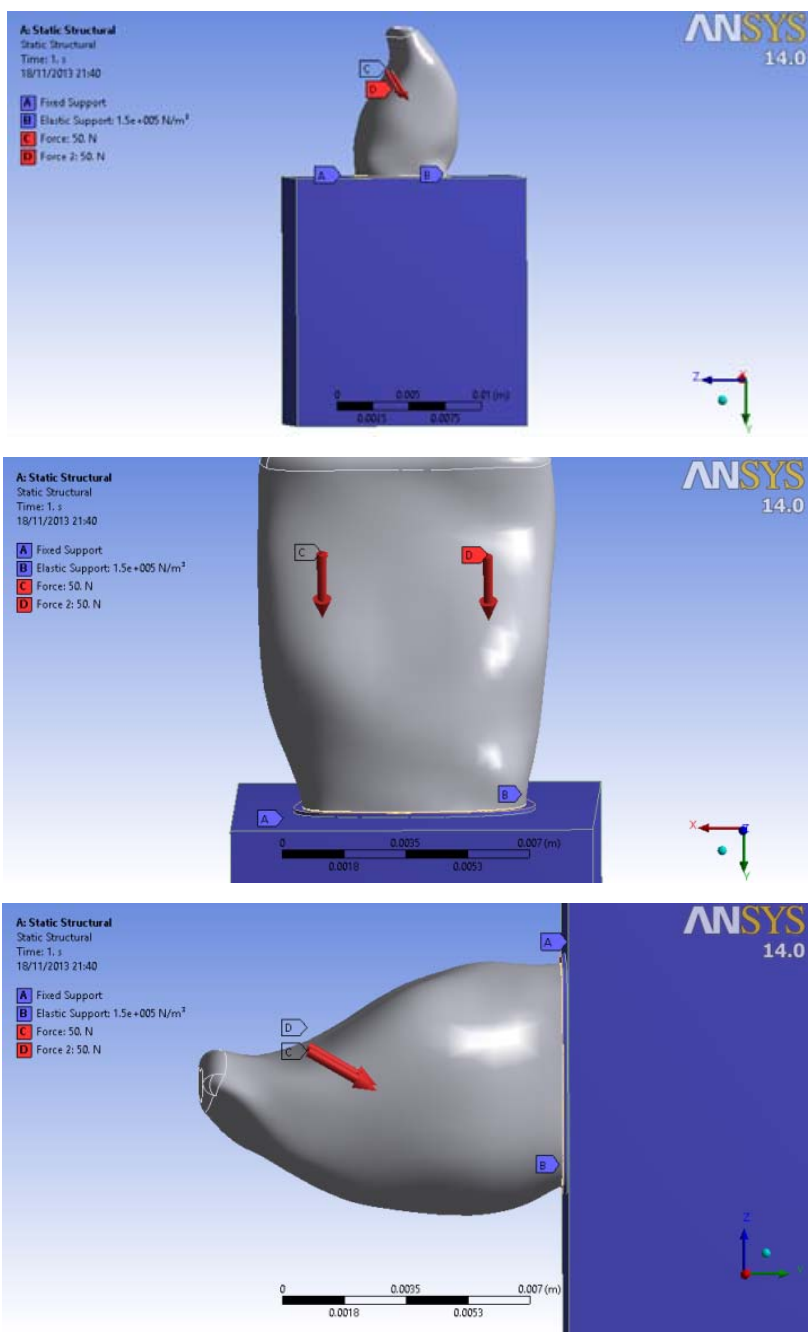

Прямой прикус
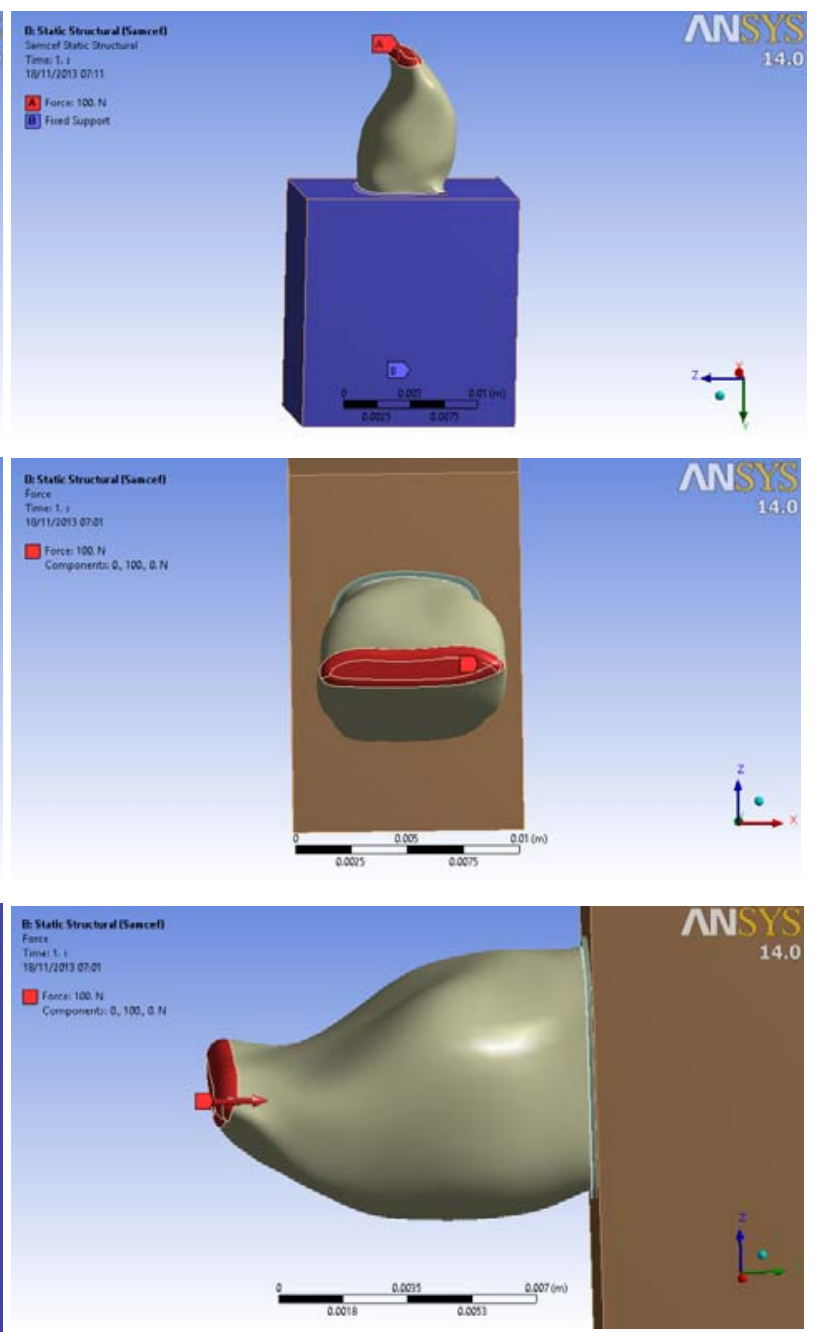

Рис. 5. Приложение нагрузки на коронковую часть зуба
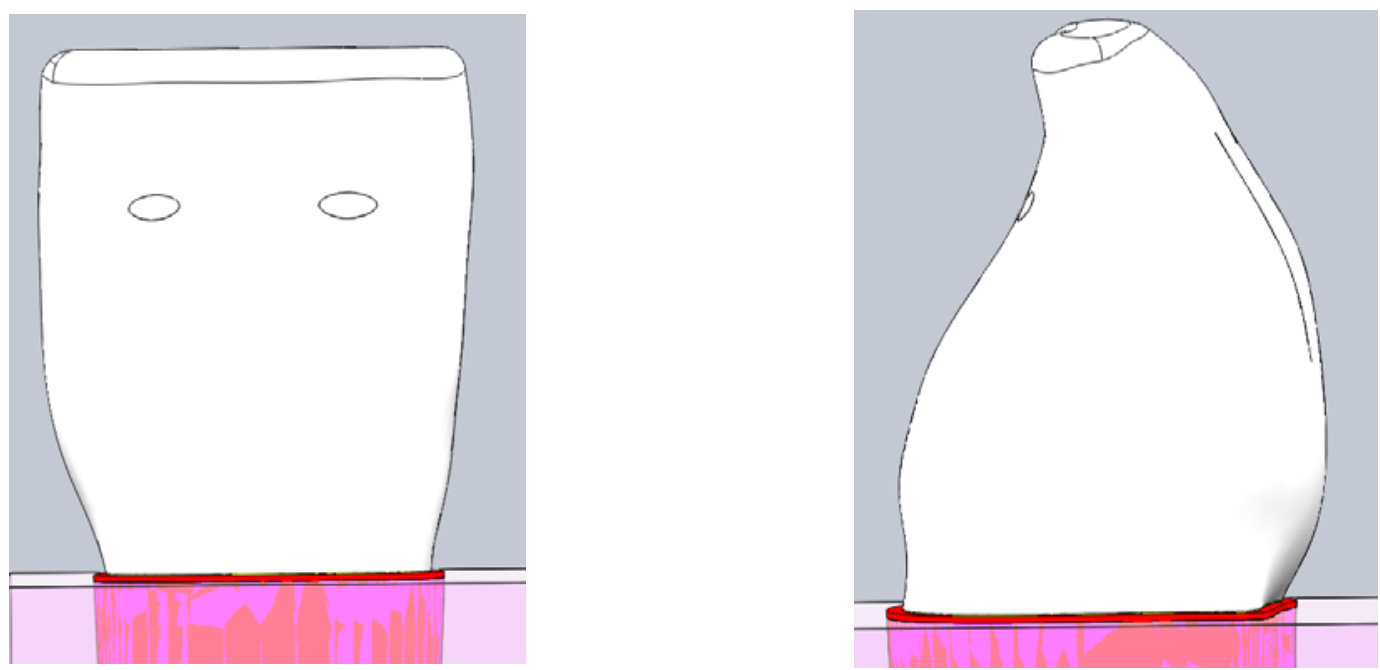

Модель поверхностей для приложения нагрузки в Solid Works. Вид сзади (слева) и сбоку (справа)

Рис. 6. Поверхности для приложения силы в случае физиологического прикуса 


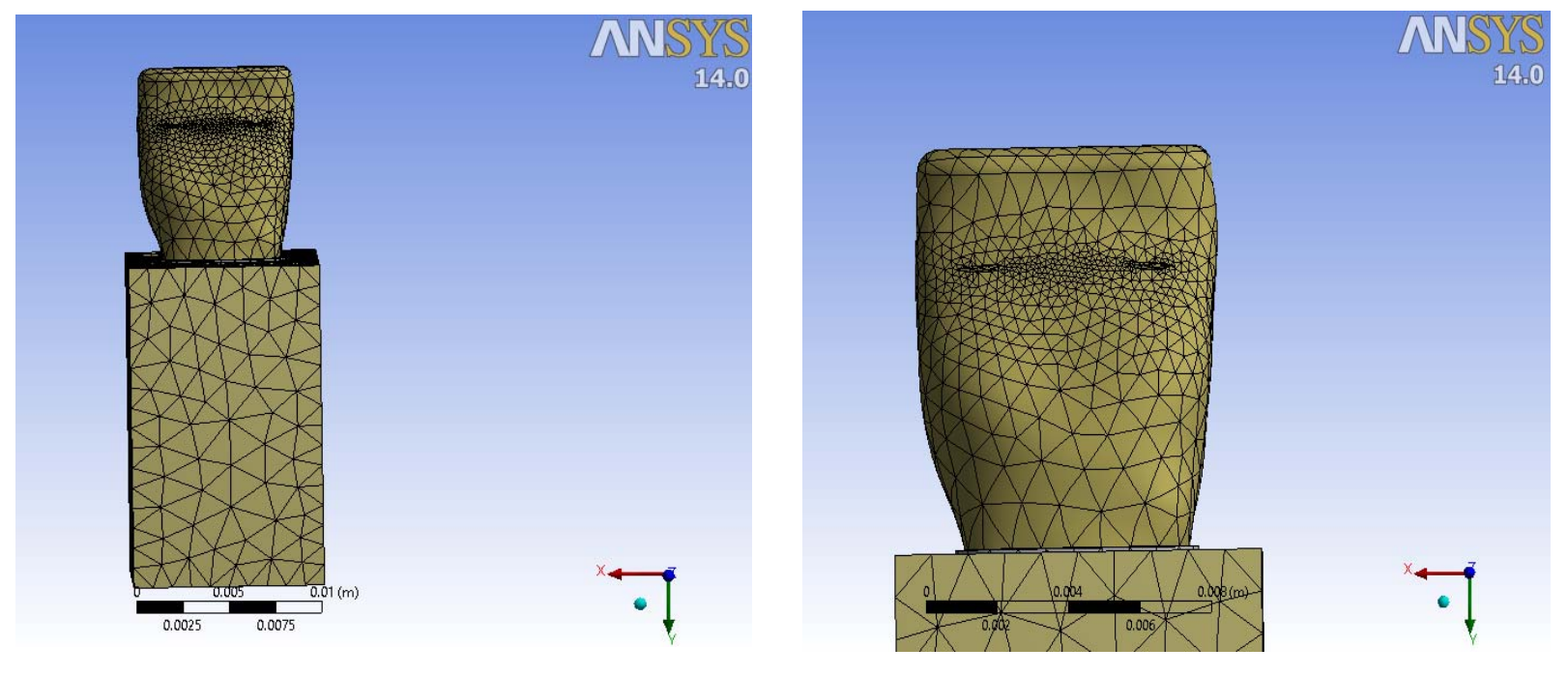

Конечно-элементная модель коронки с построенными поверхностями

Рис. 6. Окончание

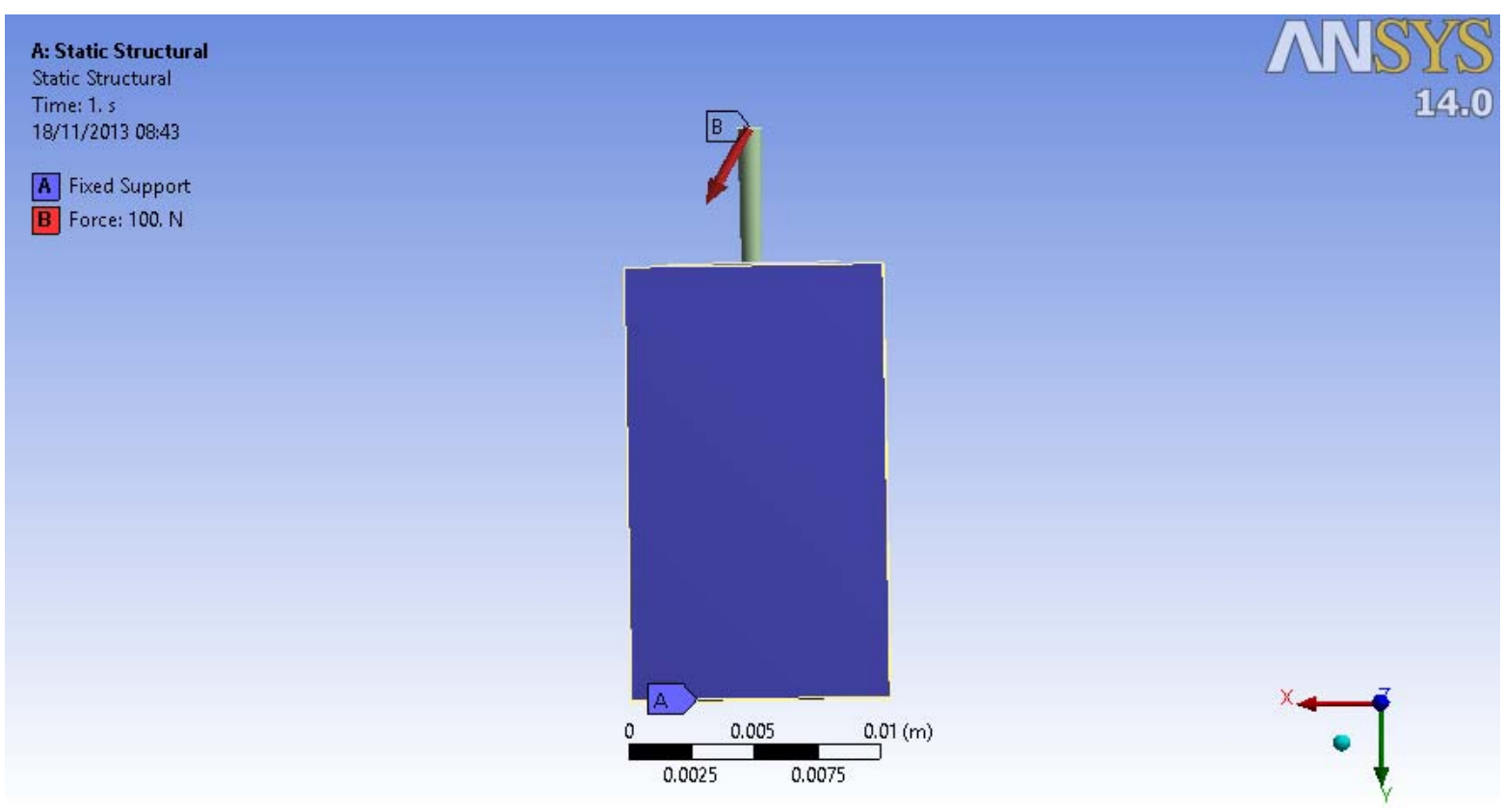

Рис. 7. Приложение нагрузки на штифт

При моделировании физиологического прикуса в среде Solid Works создавались две поверхности в форме эллипсов $(R=0,5$ м, $r=0,25$ м), к которым прикладывалась нагрузка [3] (рис. 6).

В качестве тестовой задачи был проведен сравнительный анализ напряженнодеформированного состояния, возникающего при подаче косонаправленной нагрузки непосредственно на штифт, для различных типов реставраций (рис. 7).

Изучение напряженно-деформированного состояния проводилось для разных видов реставраций.

Модель I: реставрация проводилась с помощью стекловолоконного штифта, зафиксированного в корневом канале с применением адгезивной системы Single Bond и лютингового композиционного цемента RelyX ARC (3M ESPE).

Модель II: реставрация проводилась с помощью стекловолоконного штифта, зафиксированного в корневом канале на самоадгезивный лютинговый цемент RelyX Unicem Self-Adhesive Universal Resin Cement (3M ESPE). 
Модель III: реставрация выполнялась с применением титанового штифта, зафиксированного в корневом канале на стеклоиономерный цемент.

Модель IV: реставрация осуществлялась с применением штифта из композиционного материала, зафиксированного в корневом канале лютинговым композиционным цементом $\operatorname{Rely} X A R C$.

Нагрузка подавалась под углом $30^{\circ}$ непосредственно на штифт. Модели исследовались опциями Total Deformation (полная деформация), Strain (деформация растяжения/сжатия) и Stress (напряжения).

\section{РЕЗУЛЬТАТЫ И ИХ ОБСУЖДЕНИЕ}

Анализ полученных результатов показал отсутствие существенных различий между рассмотренными видами реставраций в режиме полной деформации. Наблюдается типичная для данных армирующих конструкций картина распределения, для которой характерны максимальные значения деформации на вестибулярной стороне зуба, плавно уменьшающиеся вдоль сечения дентина до минимума на оральной стороне.

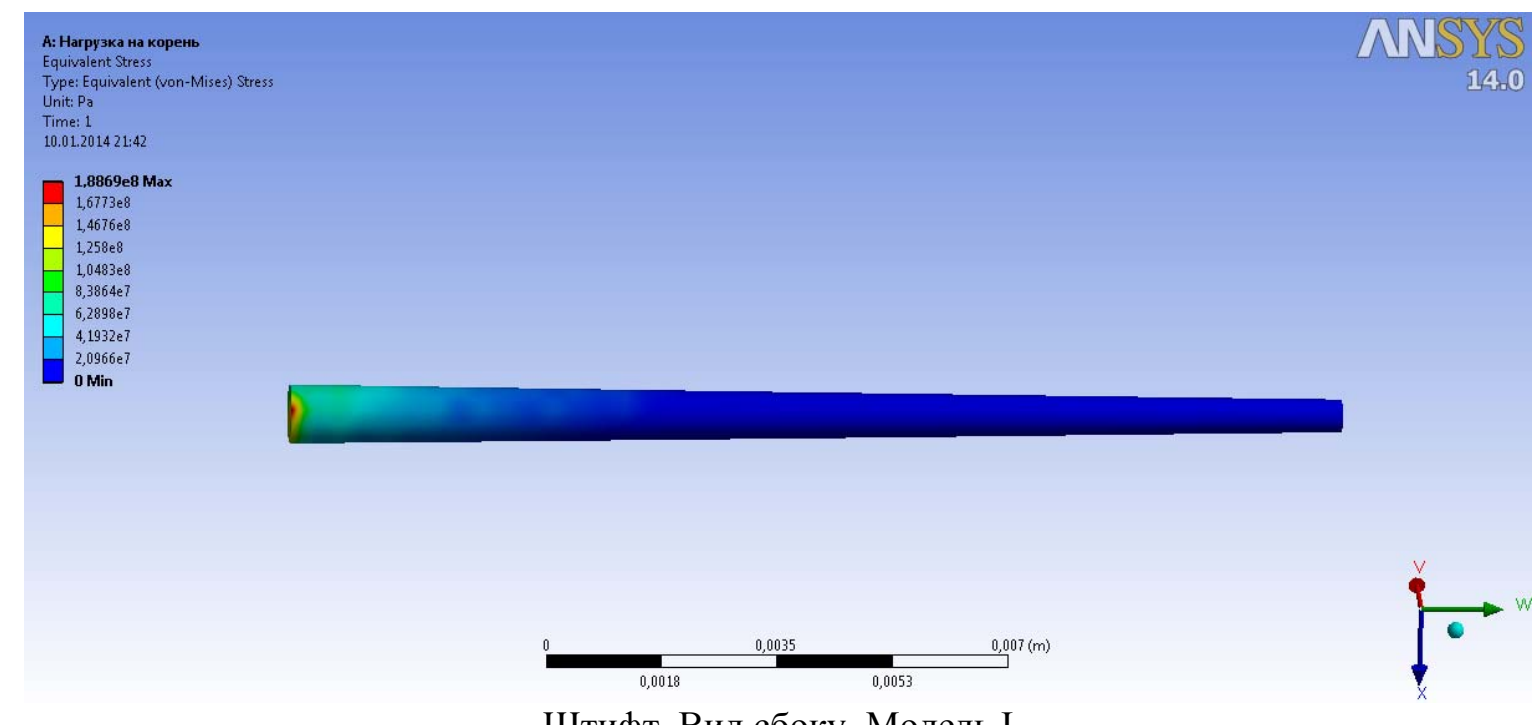

Штифт. Вид сбоку. Модель I

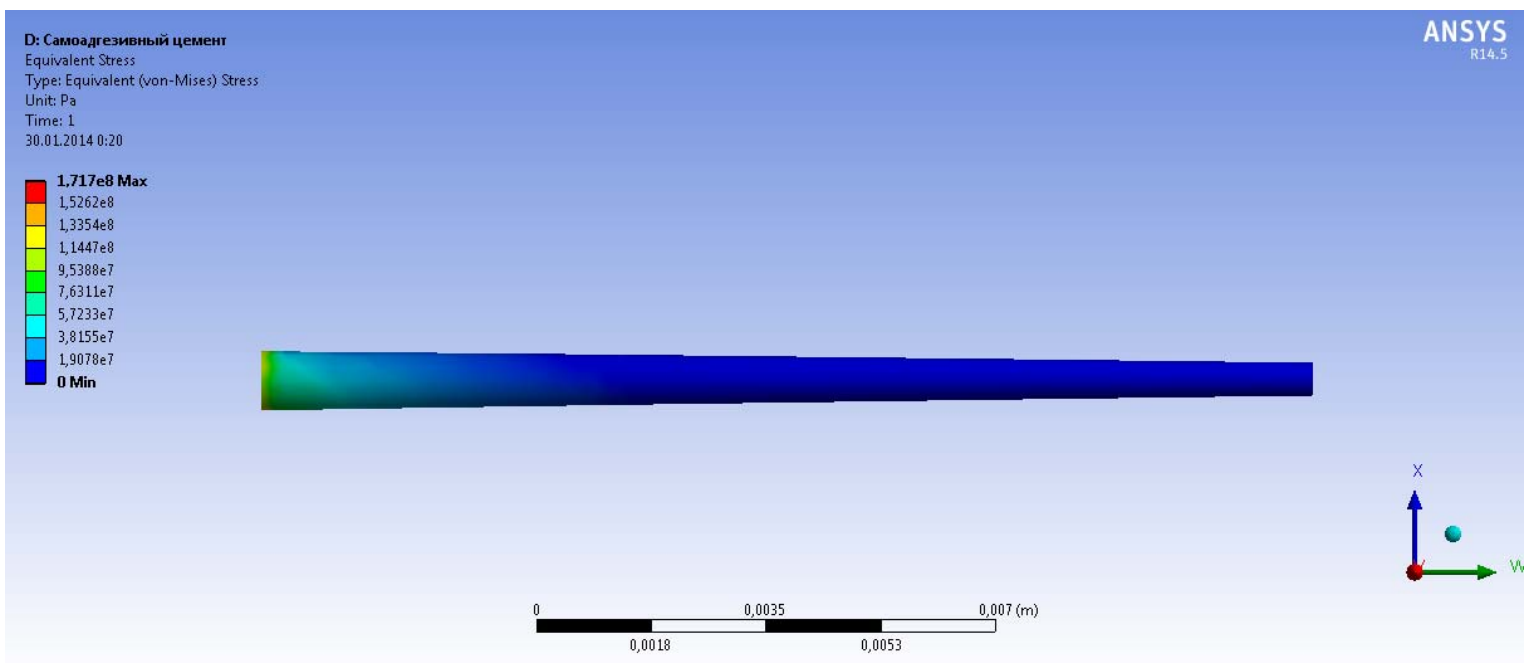

Штифт. Вид сбоку. Модель II

Рис. 8. Напряжения, возникающие в штифте под действием приложенной силы, для разных видов реставраций 


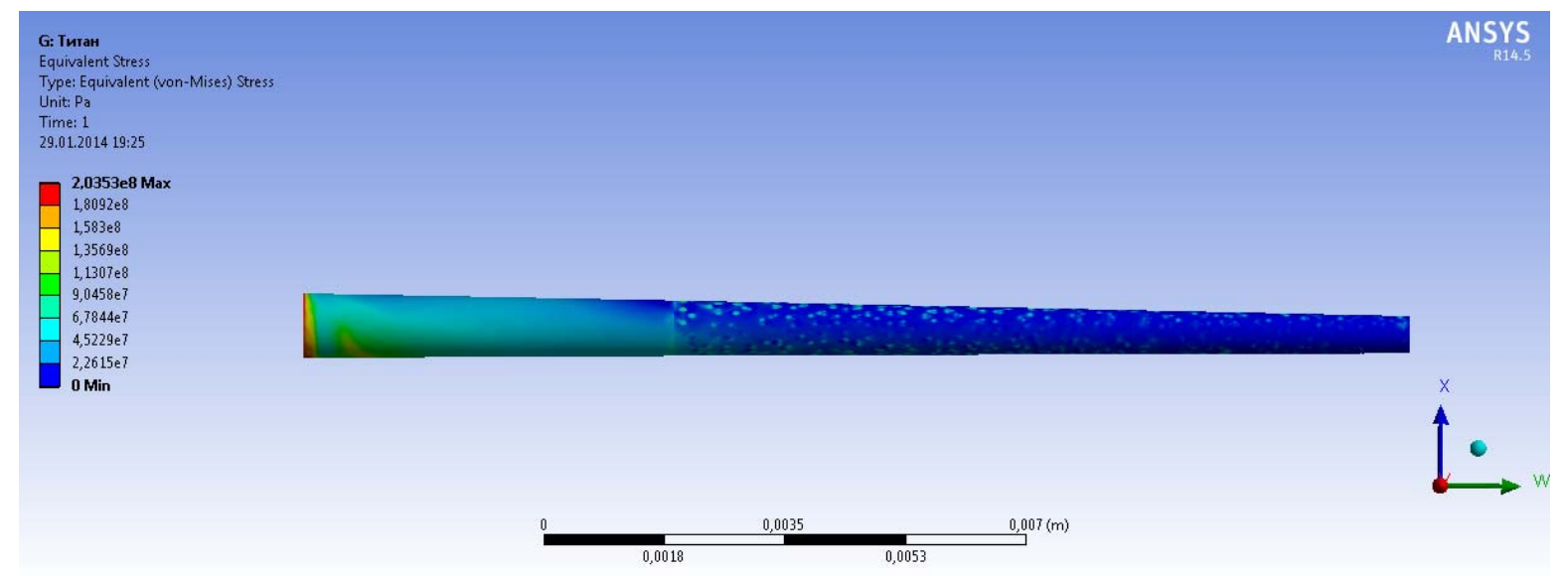

Штифт. Вид сбоку. Модель III

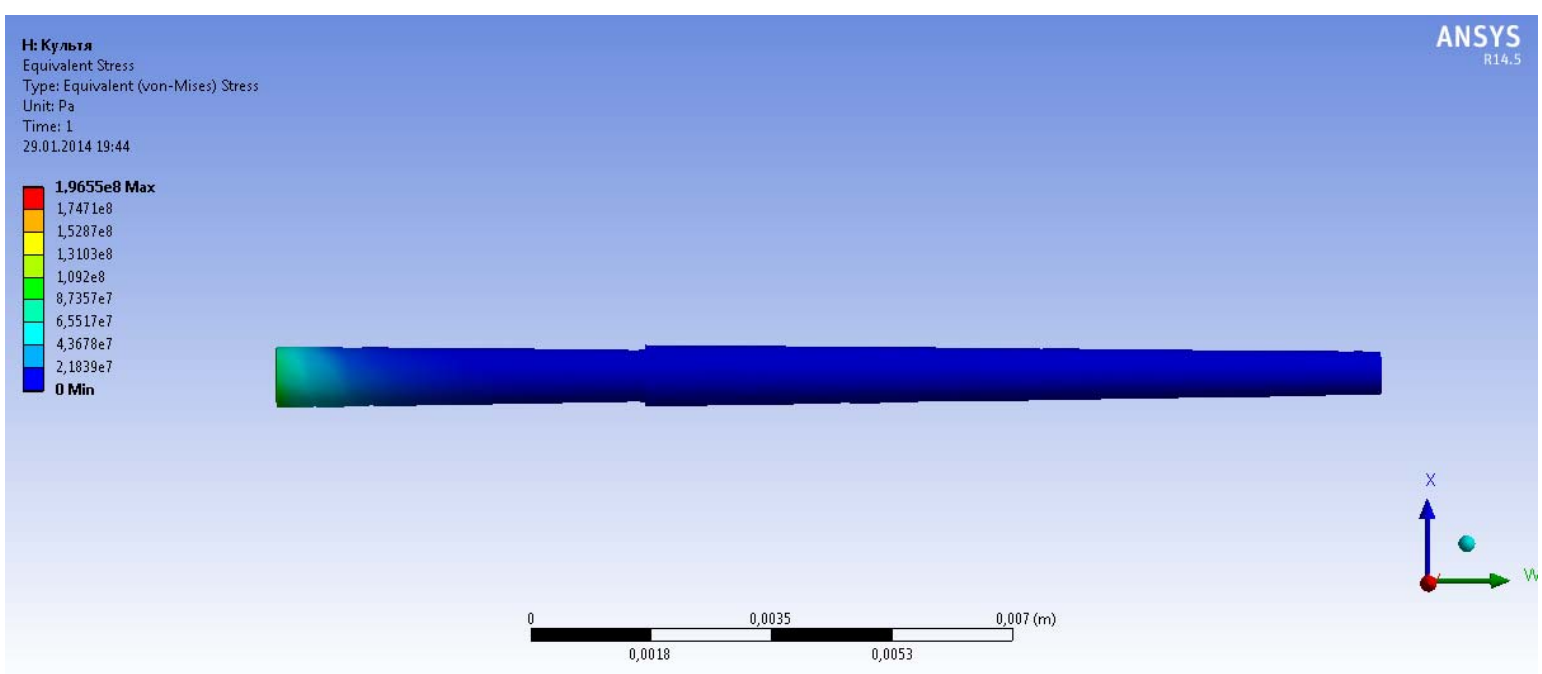

Штифт. Вид сбоку. Модель IV

Рис. 8. Окончание

Распределение деформации растяжения/сжатия для всех четырех случаев подобно: наибольшую деформацию испытывают цемент корня зуба и периодонтальная связка, тогда как другие ткани зуба и элементы реставрации деформации не подвергаются. Максимум значений приходится на вестибулярную сторону цемента корня $(\approx 0,09$ м/м) и периодонтальной связки $(\approx 0,05$ м/м $)$, минимум - с оральной стороны зуба $(\approx 0,021 \mathrm{~m} / \mathrm{M})$.

В рассматриваемых типах реставраций напряжение локализовано преимущественно в верхней части штифта. В моделях I и II оно плавно спадает к корневой части резца, а в IV модели - скачкообразно падает до нуля после прохождения верхней четверти штифта. Наибольшие значения напряжения регистрируются при использовании армирующей конструкции из титана (модель III): вплоть до $2,0358 \cdot 10^{8}$ Па на коронковой части штифта и от 0 до $1,1307 \cdot 10^{8}$ Па в корневой части с небольшими участками повышенных нагрузок в $6,7844 \cdot 10^{7}$ Па.

В верхнем основании штифта при использовании лютингового композитного цемента $\operatorname{Rely} X A R C$ (модель I) максимальные напряжения распределяются в виде треугольника в центре и очагово на вестибулярном крае $\left(1,5494 \cdot 10^{8}\right.$ Па), во II модели только с вестибулярной стороны $\left(1,5262 \cdot 10^{8}\right.$ Па). В модели III получены наибольшие значения напряжения, которые расположены по периметру титанового штифта $\left(2,0353 \cdot 10^{8}\right.$ Па). Наименьшие напряжения определяются на культевой композитной вкладке в центре и с вестибулярной стороны $-1,092 \cdot 10^{8}$ Па, с оральной $-8,7357 \cdot 10^{7}$ Па (модель IV). 
Таким образом, результаты расчетов указывают на нецелесообразность применения реставрационных конструкций типа III и IV. Титан, обладающий высоким значением модуля Юнга, существенно отличающимся от такового у естественного дентина, испытывает наибольшие напряжения, распространяющиеся практически на всю коронковую часть конструкции и верхнее основание армирующего элемента. Срок функционирования такого вида реставрации существенно ограничен ввиду предсказываемых внутрикорневых фрактур. Культевая вкладка формируется из материала, обладающего малым коэффициентом Пуассона в сочетании со сравнительно большим модулем Юнга (табл. 2), что свидетельствует о высокой степени его деформируемости. Этот факт подтверждают результаты численного эксперимента (рис. 8).

Значимых различий в поведении реставрационных конструкций, описываемых моделями I и II, выявлено не было. Однако, несмотря на кажущиеся преимущества цемента RelyX Unicem Self-Adhesive Universal Resin Cement (простота использования ввиду отсутствия необходимости нанесения адгезива отдельным этапом), с клинической точки зрения рациональнее применять именно лютинговый цемент в сочетании с адгезивом (модель I). В этом случае наблюдается картина распределения напряжений, схожая с таковой в здоровом зубе, что дает возможность выдвинуть предположение о длительном сроке службы реставрации.

Результаты расчета напряженно-деформированного состояния верхнего центрального резца с прямым прикусом для случаев применения лютингового цемента RelyX ARC и самоадгезивного цемента RelyX Unicem Self-Adhesive Universal Resin Cement представлены на рис. 9.

Модель I

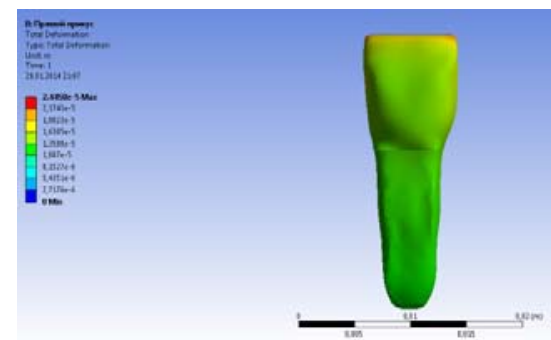

Модель II
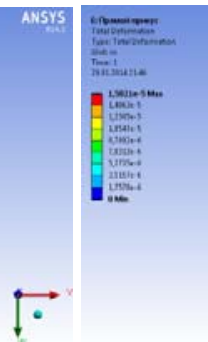

Полная деформация. Модель зуба под нагрузкой. Вид спереди
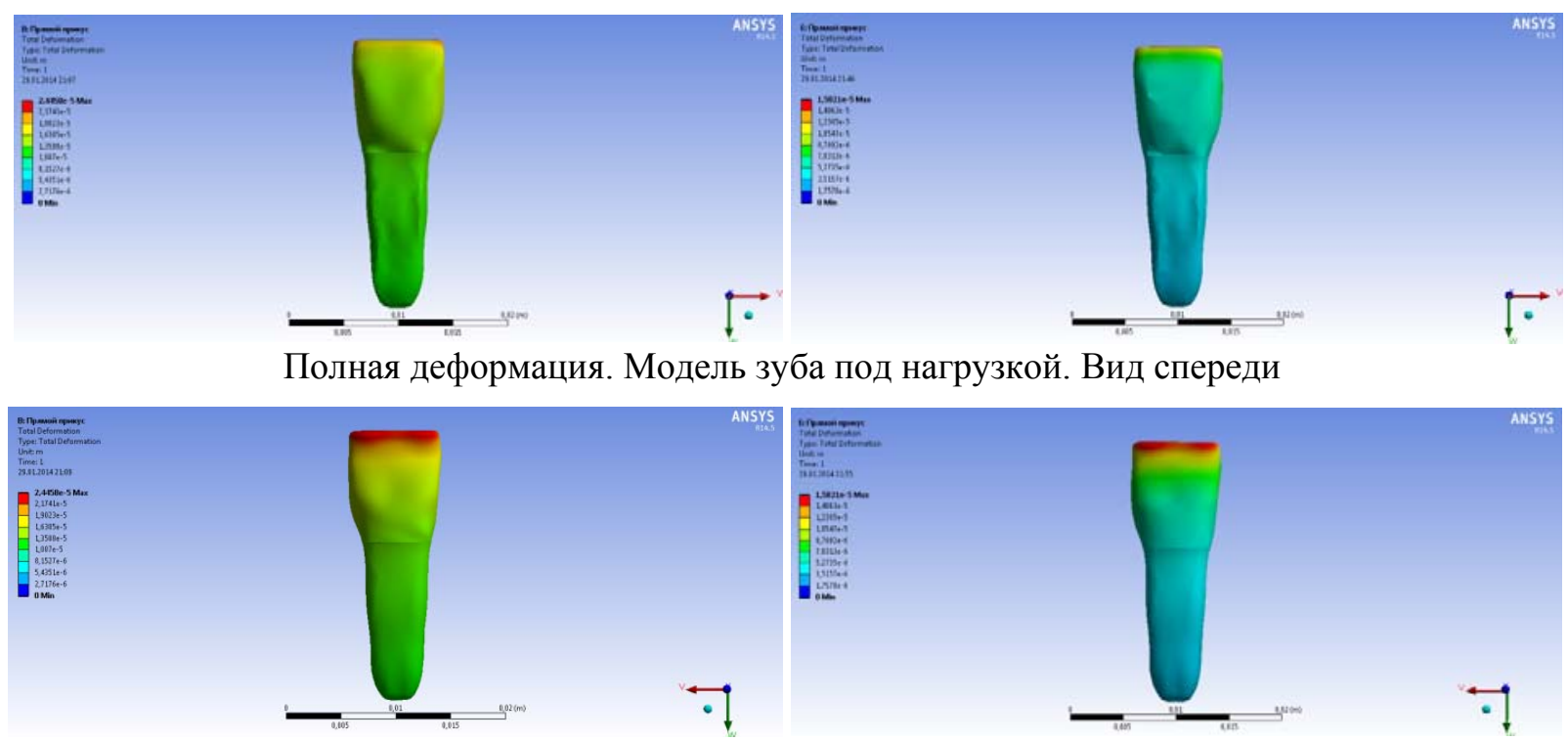

Полная деформация. Модель зуба под нагрузкой. Вид сзади
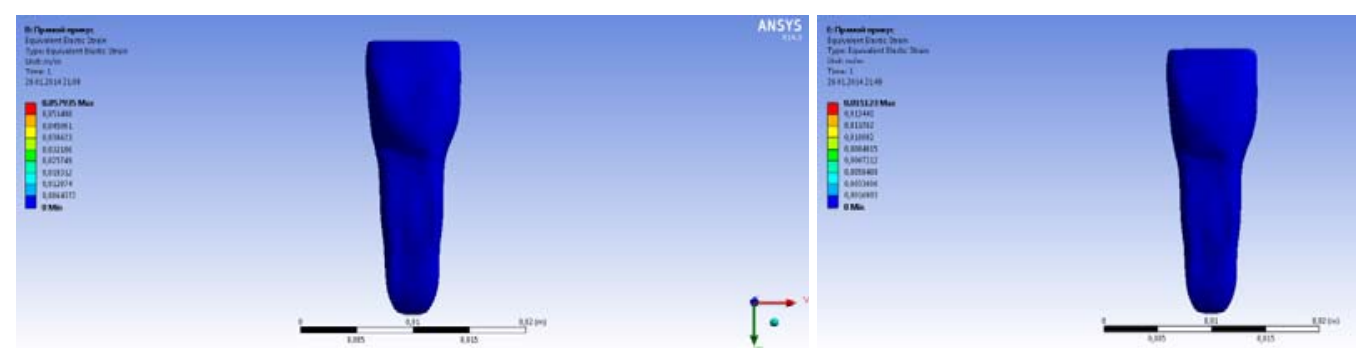

Деформация растяжения/сжатия. Модель зуба под нагрузкой. Вид спереди

Рис. 9. Изучение напряженно-деформированного состояния построенной модели в случае прямого прикуса 

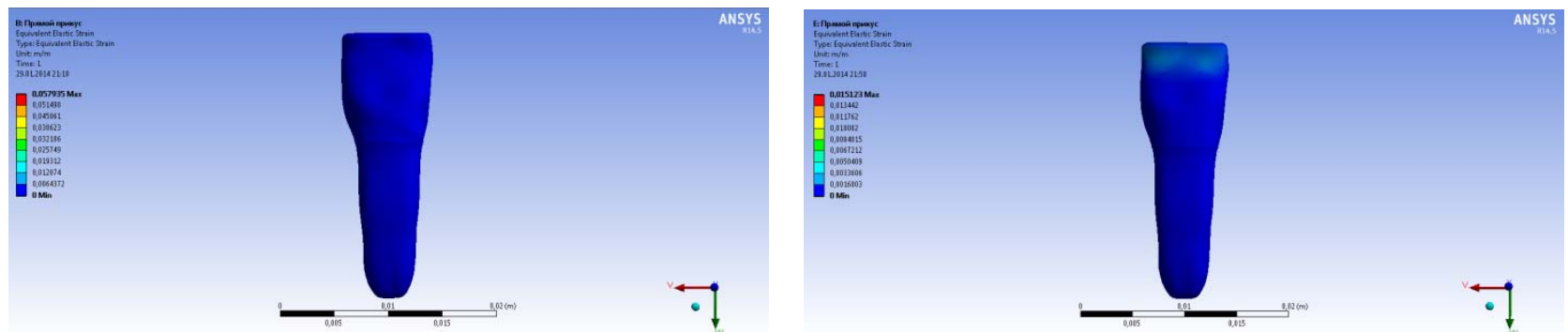

Деформация растяжения/сжатия. Модель зуба под нагрузкой. Вид сзади
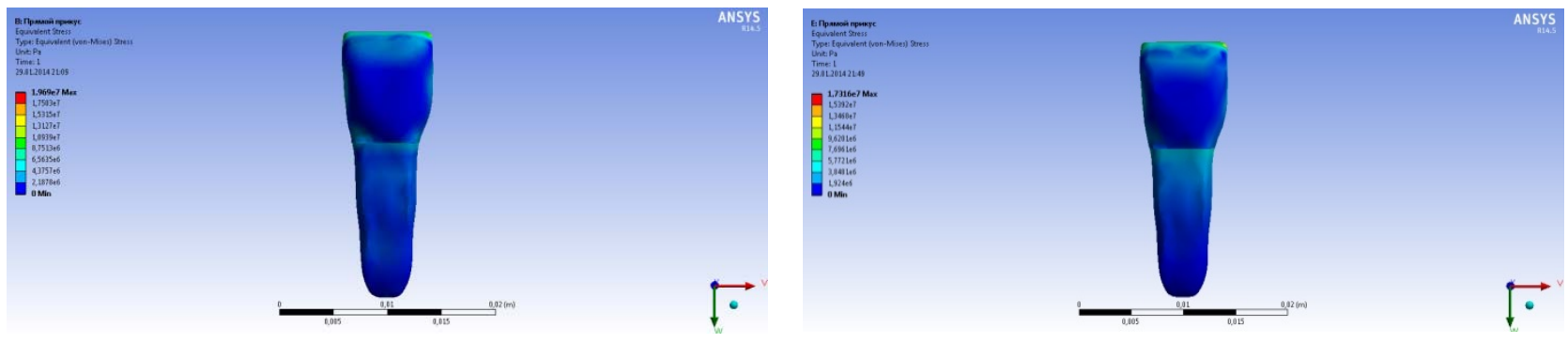

Напряжения. Модель зуба под нагрузкой. Вид спереди
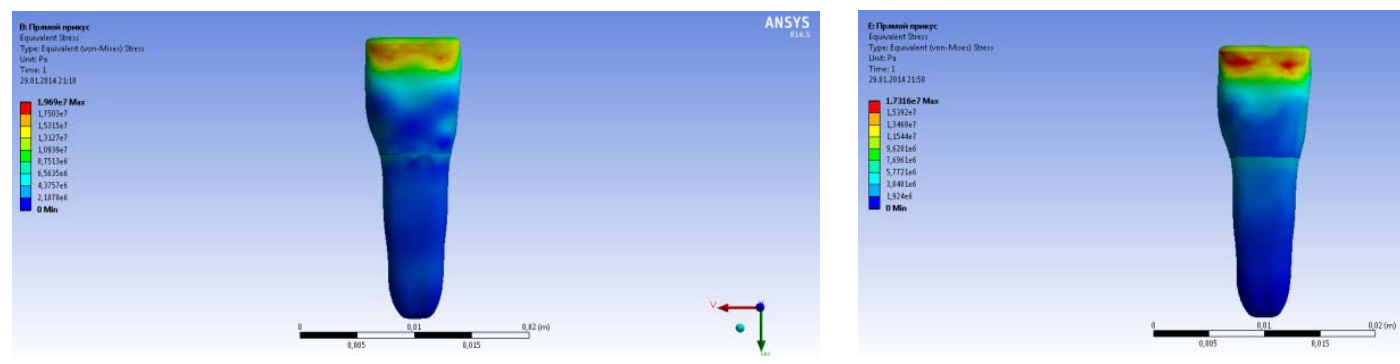

Напряжения. Модель зуба под нагрузкой. Вид сзади
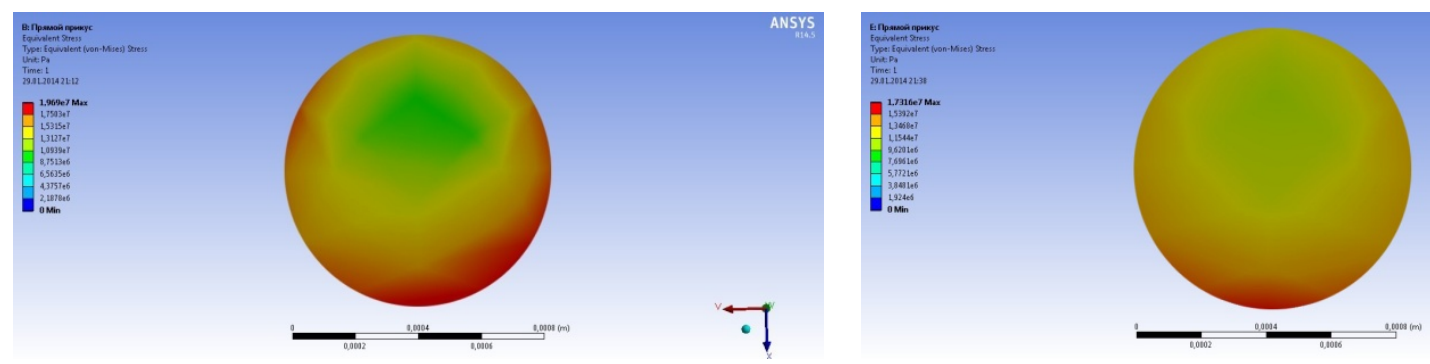

Напряжения. Штифт. Вид сверху

Рис. 9. Окончание

Результаты расчета позволили выявить:

1. Существенную разницу в величинах полной деформации в области корневого дентина: для моделей I и II определяется равномерная деформация в области шейки зуба $\left(1,6305 \cdot 10^{-5}\right.$ и $7,0313 \cdot 10^{-6}$ м соответственно) с постепенным нарастанием значений от корневой к коронковой части в диапазонах $1,3588 \cdot 10^{-5}-1,6305 \cdot 10^{-5}$ м и $5,2735 \cdot 10^{-6}-1,2305 \cdot 10^{-5} \mathrm{M}$; максимумы значений приходятся на режущие края в исследуемых моделях и составляют $2,4458 \cdot 10^{-5}$ и $1,5821 \cdot 10^{-5}$ м. В модели I регистрируется высокая, но плавно возрастающая нагрузка на коронковую часть, а в модели II - резкое увеличение показателя в верхней половине коронки с оральной стороны.

2. Для моделей I и II максимумы деформации растяжения/сжатия регистрируются в области цемента корня зуба и составляют 0,0579 и 0,0151 соответственно, уменьшаясь в зоне периодонта до 0,0257 и 0,0084 . В случае II 
зафиксировано небольшое увеличение нагрузки в верхней трети коронковой части зуба с оральной стороны (вплоть до 0,0017), тогда как в модели I растяжение/сжатие коронки полностью отсутствует. Остальные ткани и элементы реставрационных конструкций деформации растяжения/сжатия не испытывают.

3. Для моделей I и II дентин в области шейки зуба испытывает напряжения $4,3757 \cdot 10^{6}$ и $3,8481 \cdot 10^{6}$ Па соответственно, при этом нагрузки в модели II распределены равномерно, в случае I - по периферии; максимумы напряжений определяются в верхних третях коронковых частей с оральной стороны и в верхнем основании штифта вплоть до $1,9690 \cdot 10^{7}$ и $1,7316 \cdot 10^{7}$ Па. При этом для модели I в верхней трети коронковой части реставрированного зуба напряжения распределены более равномерно по сравнению с моделью II; наибольшие значения приходятся на границу верхнего основания штифта с оральной стороны, а в модели II напряжение локализовано на большой площади с максимумом на оральном краю штифта. Диапазон напряжений по длине армирующего элемента широк: $4,3757 \cdot 10^{6}-1,9690 \cdot 10^{7}$ и $3,8481 \cdot 10^{6}-1,7316 \cdot 10^{7}$ Па для рассматриваемых моделей соответственно от нижнего основания к верхнему, но в случае использования самоадгезивного цемента (модель II) большие значения регистрируются на более длинном промежутке (по всей коронковой части штифта).

Таким образом, в случае прямого прикуса при фиксации армирующего элемента в корневом канале целесообразно использовать лютинговый цемент $\operatorname{RelyX} A R C$ с нанесением адгезивной системы Single Bond отдельным этапом, что обеспечивает более равномерное распределение напряжений вдоль корневого канала и, как следствие, снижает вероятность образования фрактур (см. рис. 9).

На рис. 10 представлены результаты расчета напряженно-деформированного состояния реставрированного верхнего центрального резца в условиях физиологического прикуса при использовании лютингового цемента $\operatorname{RelyX} A R C$ с нанесением адгезивной системы отдельным этапом и самоадгезивного цемента Rely $X$ Unicem Self-Adhesive Universal Resin Cement.

Модель I

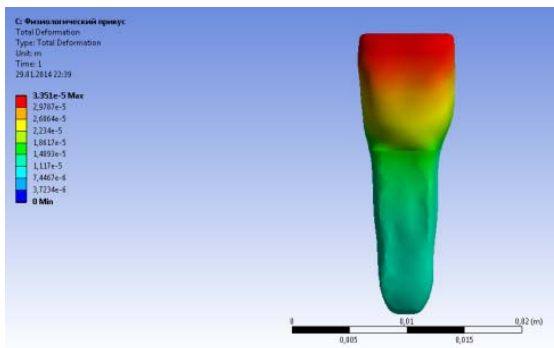

Модель II

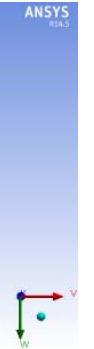

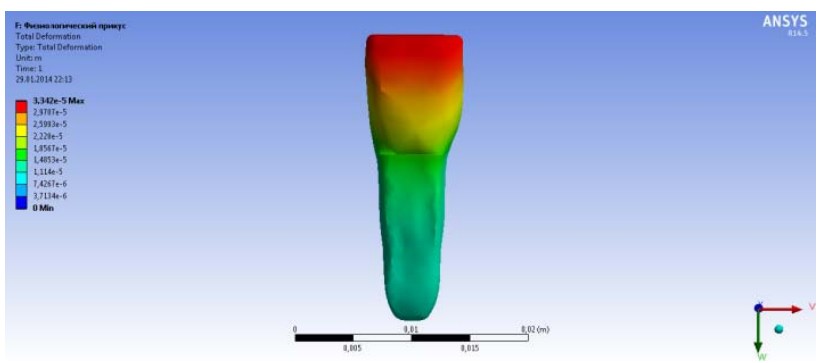

Полная деформация. Модель зуба под нагрузкой с фронтальной стороны
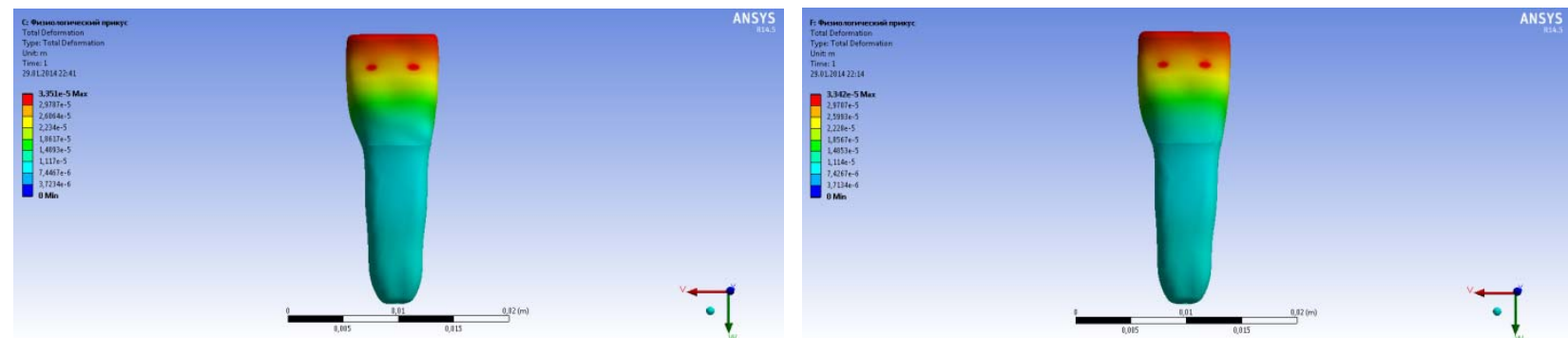

Полная деформация. Модель зуба под нагрузкой с оральной стороны

Рис. 10. Изучение напряженно-деформированного состояния построенной модели в случае физиологического прикуса 


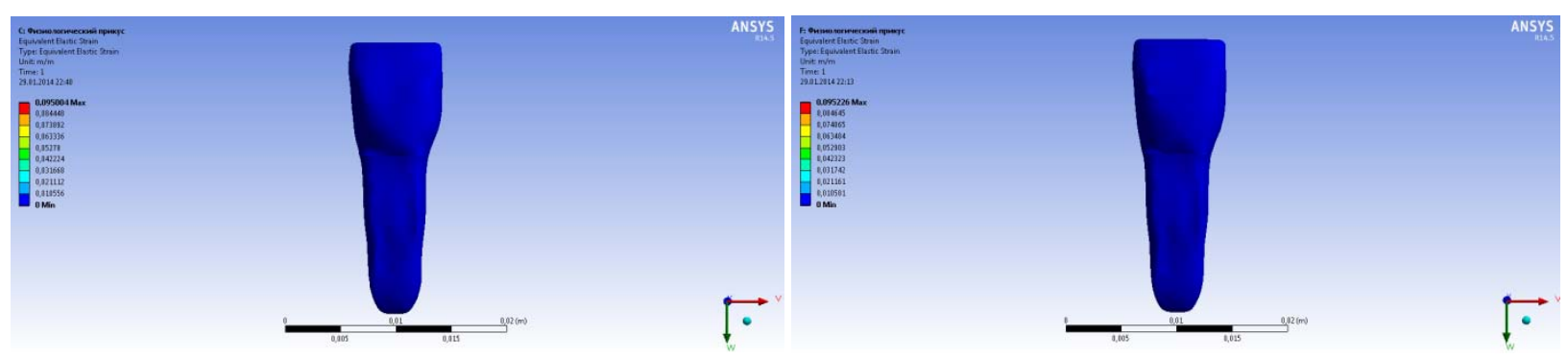

Деформация растяжения/сжатия. Модель зуба под нагрузкой с фронтальной стороны

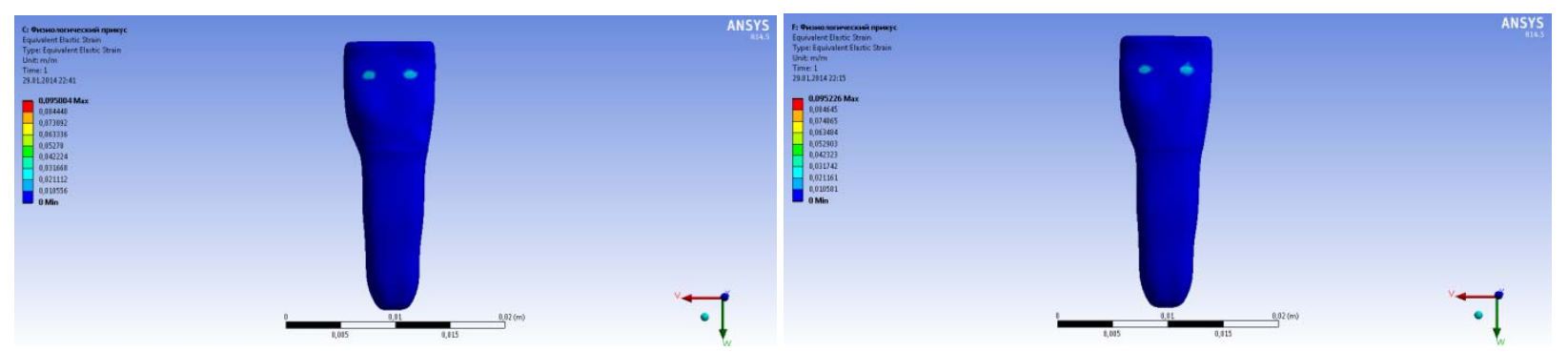

Деформация растяжения/сжатия. Модель зуба под нагрузкой с оральной стороны

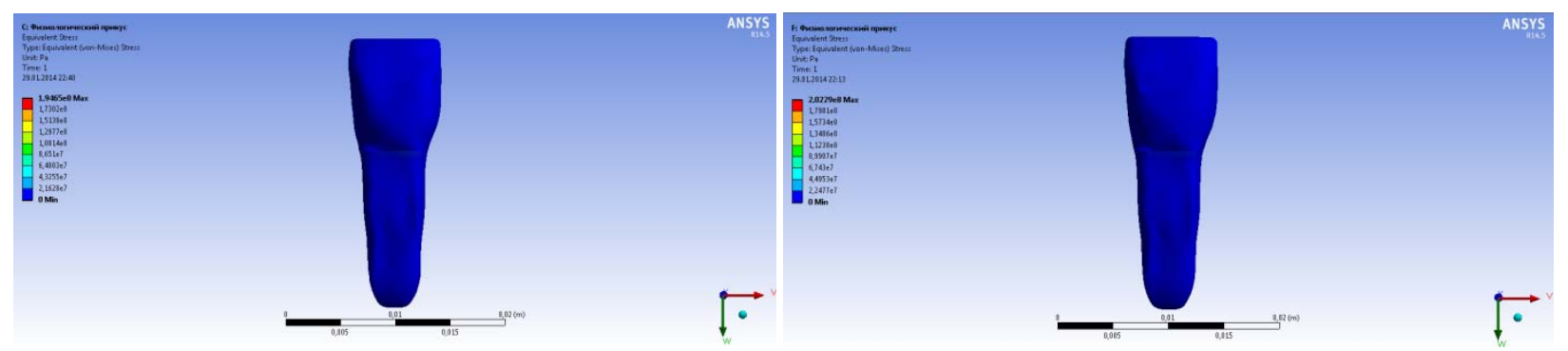

Напряжения. Модель зуба под нагрузкой с фронтальной стороны

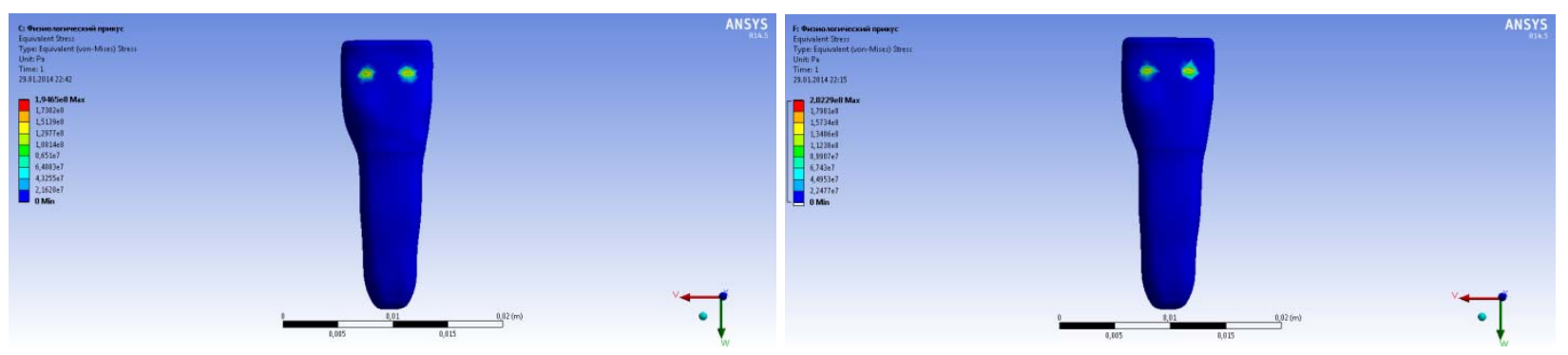

Напряжения. Модель зуба под нагрузкой с оральной стороны

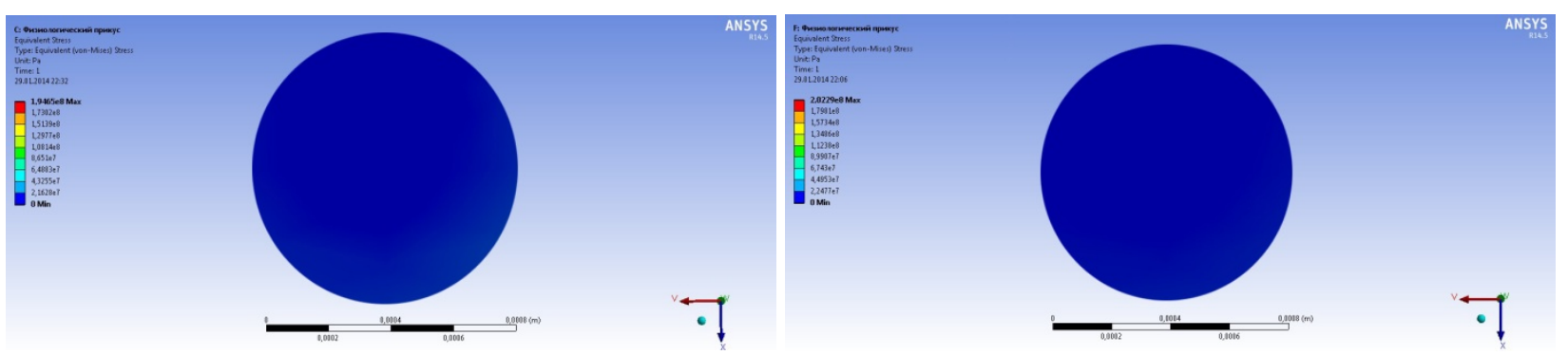

Напряжения. Штифт. Вид сверху

Рис. 10. Окончание 
Результаты расчетов указывают на то, что:

1. Для моделей I и II полная деформация распределяется неравномерно в тканях дентина, локализованного в области шейки зуба, изменяясь от $1,86 \cdot 10^{-5} \mathrm{M}$ с вестибулярной поверхности до $1,11 \cdot 10^{-5}$ м - с оральной; при этом максимумы нагрузки приходятся на верхнюю половину коронки с вестибулярной стороны зуба, режущий край и на контактные области $\left(3,3510 \cdot 10^{-5}\right.$ и $3,3420 \cdot 10^{-5}$ м для моделей I и II соответственно); в нижней трети коронковой части зуба наибольшие значения деформации регистрируются с вестибулярной стороны $\left(1,8567 \cdot 10^{-5} \mathrm{M}\right)$, а наименьшие с оральной $\left(1,11 \cdot 10^{-5} \mathrm{M}\right)$ для указанных моделей.

2. Деформацию растяжения/сжатия испытывают не только цемент корня и периодонтальная связка, но и контактная зона $(0,0316$ и 0,0317 для моделей I и II соответственно), при этом максимальные значения $(0,095)$ определяются именно с вестибулярной стороны и приходятся на цемент корня, спадая до 0,052 на периодонтальной связке; минимум $(0,0211)$ зафиксирован с оральной стороны.

3. Для моделей I и II напряжения наблюдаются исключительно в контактной зоне, распределяясь от центра $\left(1,9465 \cdot 10^{8}\right.$ и $2,0229 \cdot 10^{8}$ Па соответственно) к периферии $\left(6,4883 \cdot 10^{7}\right.$ и $6,7430 \cdot 10^{7}$ Па соответственно).

В случае физиологического прикуса видимых отличий в использовании самоадгезивного RelyX Unicem Self-Adhesive Universal Resin Cement и лютингового композиционного цемента Rely $X A R C$ в сочетании с адгезивной системой Single Bond также не обнаруживается.

Полученные результаты соответствуют известным в литературе данным $[1,2,7,9]$.

Таким образом, в представленном исследовании с позиции биомеханики изучено влияние различных адгезивных технологий, применяемых при фиксации штифта в корневом канале, на распределение напряжений и деформаций в структурах восстановленного зуба под внешней окклюзионной нагрузкой для различных видов прикуса.

Определены оптимальные характеристики адгезивного соединения, позволяющие минимизировать напряжения, появление возможных фрактур в корневом канале и увеличить срок службы реставрации. В частности, выявлены преимущества использования адгезивной системы Single Bond в сочетании с лютинговым цементом RelyX ARC перед самопротравливающей композиционной системой RelyX Unicem SelfAdhesive Universal Resin Cement [2].

\section{СПИСОК ЛИТЕРАТУРЫ}

1. Меликян Г.М. Клинико-лабораторное обоснование реставрации дефектов режущего края передней группы зубов с применением сеточно-армирующего элемента: дис. ... канд. мед. наук. - М., 2008. $157 \mathrm{c}$.

2. Наумович С.А., Крушинина Т.В., Богдан С.И. Изучение напряженно-деформированных состояний в верхнем центральном резце, восстановленном с помощью различных стандартных штифтов, на основе метода конечно-элементного анализа // Медицинский журнал. - 2009. - № 3. - С. $259-261$.

3. Чилинкин В.Н. Разработка алгоритма выбора современных материалов и технологий для реставрации зубов: автореф. дис. ... канд. мед. наук. - М., 2009. - 50 с.

4. Catavic A., Seifert D., Poljak-Guberina R. Influence of sex, age and presence of functional units on optical density and bone height of the mandible in the elderly // Acta Stomatologica Croatica. - 2002. - Vol. 36, № 3. - P. 327-328.

5. De Castro Albuquerque R., De Abreu Polleto L.T. Stress analysis of an upper central incisor restored with different posts // Journal of Oral Rehabilitation. - 2003. - № 30. - P. 936-943.

6. Dietschi D., Duc O., Krejci I., Sadan A. Biomechanical considerations for the restoration of endodontically treated teeth: a systematic review of the literature - part 2 (Evaluation of fatigue behavior, interfaces, and in vivo studies) // Quintessence International. - 2008. - Vol. 39, № 2. - P. 117-129.

7. Guang-Quan Song. Three-dimensional finite element stress analysis of post-core restored endodontically treated teeth: MS thesis. - Winnipeg, 2005. - 152 p. 
8. Pierrisnard L., Bohin F., Renault P., Barquins M. Corono-radicular reconstruction of pulpless teeth: A mechanical study using finite element analysis // Journal of Prosthetic Dentistry. - 2002. - Vol. 88, № 4. - P. 442-448.

9. Porojan S., Topala F., Porojan L. Finite element analysis of roots restored with metallic posts and ceramic crowns during occlusal movement // Recent Advances in Computer Science. - 2002 . - № 14. - P. $193-196$.

10. Toparli M. Stress analysis in a post-restored tooth utilizing the finite element method // Journal of Oral Rehabilitation. - 2003. - № 30. - P. 470-476.

\section{BIOMECHANICAL SIMULATION OF THE STRESS-STRAIN RESPONSE IN RESTORED ENDODONTICALLY TREATED TEETH UNDER NORMAL OCCLUSAL LOADING}

\section{N.O. Bessudnova, E.E. Tsiporukha, S.B. Venig (Saratov, Russia)}

In the present study, the computational biomechanics methods have been applied to evaluate the reliability of restorative constructions of endodontically treated teeth. The numerical design results of biomechanical behavior of a restored upper central incisor under normal chewing loadings of $100 \mathrm{~N}$ for different types of occlusion were presented. For these purposes a three-dimensional model of the restored tooth including elements of hard tooth tissues, periodontal ligament with surrounding alveolar bone structures and post-core restoration elements was constructed using a Solid Works CAD system. Using this model as a prototype, a variety of materials' combinations and restoration designs under occlusal loadings were numerically simulated using Finite element software ANSYS. In particular, the influence of materials of post element and luting cement as well as post fixation methods in root canal on restored tooth functional characteristics was investigated. For the edge-to-edge and physiological bytes the comparison of stress-strain response for the teeth restored using a luting composite polymeric cement RelyX ARC (3M ESPE), which intended the destroyed dentine layer (the smear layer) removal before the application of the layer of adhesive system, and a luting composite polymeric cement RelyX Unicem Self-Adhesive Universal Resin Cement ( $3 M$ ESPE), which remained the smear layer, was carried out. The $3 D$-model designed could be applied for pre-clinical evaluation and comparison of the longevity for post-core restorative constructions of different type.

Key words: biomechanical modelling, prototyping, numerical methods, finite element method, restorative dentistry, adhesive materials and technologies, reinforcing constructions. 